\title{
PENANAMAN NILAI-NILAI AKHLAK BERBASIS KEGIATAN SUNNAH RASULULLLAH DI SEKOLAH DASAR
}

\author{
Novela Aditiya ${ }^{1}$, Sutrisno $^{2}$ \\ ${ }^{1}$ UIN Sunan Kaligaja, Yogyakarta, Indonesia \\ ${ }^{2}$ Dosen, UIN Sunan Kaligaja Yogyakarta, Indonesia \\ Email:21204081014@student.uin-suka.ac.id ${ }^{1}$, sutrisno@uin-suka.ac.id ${ }^{2}$
}

\begin{abstract}
Abstrak
Penelitian ini bertujuan untuk mengetahui penanaman nilai-nilai akhlak berbasis sunah rasulullah di Sekolah Dasar Islam Terpadu (SD IT) Sahabat Qur'an. Penelitian ini mengunakan metode penelitian kulitatif dengan pendekatan deskriptif analitis, data penelitian didapatkan dari observasi dan wawancara. Informan dalam penelitian ini terdiri dari 3 guru kelas dan guru pendamping. Hasil informasi dari informan melalui tahapan analisis reduksi data, penyajian dan penarikan kesimpulan. Penelitian ini menyimpulkan bahwa penanaman nilainilai akhlak berbasis kegiatan sunnah rasulullah melalui 5 kegiatan yaitu 1)penguatan akidah yang bersumber dari ajaran Allah SWT, 2)pembiasan shalat sunah dhuda, qobliyah, badiyah, dan shalat wajib zuhur dan ashar yang dilaksankan dengan berjamaah, 3)kegiatan tahsin dan tahfiz yang telah ditentukan kegiatannya sesuai jadwal, 4)pakaian yang sesuai dengan syariat Islam dan pemisahan ruang kelas laki-laki dan perempuan, 5)akhlak dan abad Islam yang dilakukan berdasarkan sunnah rasulullah. Hasil penelitian ini berkontribusi terhadap ragam pengembangan Pendidikan karakter berbasis sunnah di dalam proses pembelajaran di sekolah dan madrasah.
\end{abstract}

Kata kunci: nilai -nilai akhlak, sunnah rasulullah, sekolah dasar

\begin{abstract}
This research aims to find out the cultivation of moral values based on the sunah of the Prophet in SD IT Sahabat Qur'an. This study uses skinative research with a descriptive approach, research data obtained from observations, and interviews. The informant in the study consisted of 3 classroom teachers and a companion teacher. The results of information from informants through the stageof data reductionanalysis, presentation and withdrawal of conclusions. This research concluded that the cultivation of moral values based on the sunnah activities of the Prophet through 5 activities 1)strengthening the creed derived from the teachings of Allah SWT, 2)the refraction of sunah dhuda, qobliyah, badiyah, and obligatory prayers zuhur and ashar ayng is carried out with congregation, 3)tahsin and tahfiz activities that have been determined activities according to schedule, 4)clothing in accordance with Islamic Sharia and the separation of male and female classrooms, 5)The morals and centuries of Islam are carried out based on the sunnah of the Prophet.
\end{abstract}

Keywords: moral values, sunnah rasulullah, primary school

\section{PENDAHULUAN}

Sistem pendidikan di masa covid 19 mengalami perubahan pada proses pembelajaran, proses pembelajaran dilakukan dengan daring melalui berbagai macam aplikasi internet. Perubahan proses pembelajaran mengakibabkan banyak pihak sekolah dan pendidik yang hanya memberikan materi

Al-Madrasah: Jurnal Ilmiah Pendidikan Madrasah Ibtidaiyah Vol. 6, No. 1, Januari-Maret 2022 
Novela Aditiya, Sutrisno : Penanaman Nilai-Nilai Akhlak Berbasis Kegiatan Sunnah Rasulullah di Sekolah Dasar

pembelajaran yang mengembangkan aspek kognitif peserta didik. Nilai-nilai akhlak peserta didik tidak diutamakan dalam pembelajaran daring. Berdasarkan observasi yang dilakukan sistem pembelajaran daring yang dilakukan oleh sekolah dasar umum dan sekolah dasar Islam terpadu mengalami perbedaan yang signifikan. Hasil observasi yang dilakukan di SD IT Sahabat Qur'an proses pembelajaran yang dilakukan pada saat daring banyak hal yang dilakukan oleh pendidik agar penerapan nilai akhlak tetap dijalankan dengan baik walaupun pembelajaran dilakukan dengan daring.

Pendidikan akhlak diberikan binaan dari sejak dini menjadi pondasi dalam menjalankan kehidupan. Pada proses pembelajaran ditengah pandemic covid 19 pendidikan akhlak di sekolah dasar yang umum tidak diutamakan karena pendidik lebih mengutamakan perkembangkan pendidikan kognitif peserta didik. Permasalah ini membuat nilai-nilai akhlak peserta didik mengalami kemorosotan. Pihak sekolah terutama pendidik dapat menanamkan nilai akhlak yang baik dilakukan dengan kebiasan yang dilakukan saat berada di sekolah dan dapat diterapkan dilingkungan keluraga ${ }^{1}$. Kegiatan yang dilakukan disekolah untuk menanamkan nilai akhlak peserta didik dapat diterapkan sesuai dengan pembiasan akhlak taulan dan Nabi Muhammad SAW ${ }^{2}$. Nilai akhlak yang ditanamkan pada diri peserta didik ketulusan, kejujuran, kesopanan, keramahan, dan rasa kasih sayang kepada semua manusia ${ }^{3}$.

Membina akhlak anak dapat mencontohkan taulan dari rasulullah SAW dari kebiasan yang dilakukannya. Rasullulah diutus ke muka bumi untuk menyempurnakan akhlak umat manusia yang setiap masa akhlak mengalami kemorosotan terutama pada generasi saat ini ${ }^{4}$. Alquran menjelaskan bahwa nabi Muhammad SAW datang ke muka bumi untuk memyempurnakan akhlak serta sebagai sauri taulan umat manusia ${ }^{5}$, surat Alquran at-taubah ayat 128:

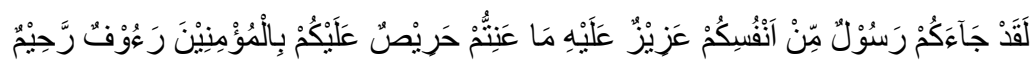
Artinya: Sungguh, telah datang kepadamu seorang rasul dari kaummu sendiri, berat terasa oleh penderitaan yang kamu alami, (dia) sangat menginginkan (keimanan dan keselamatan) bagimu, penyantun dan penyayang terhadap orang-orang yang beriman (Surat At-Taubah :128)

Islam mengajarkan bahwa akhlak mendapat posisi yang sangat penting sehingga setiap upaya yang dilakukan dalam pendidikan Islam bermuara pada pembentukan akhlakul karimah yang dilandasi

1 Fathul Zannah, "Integrasi Nilai-Nilai Pendidikan Karakter Berbasis Al Qur'an,” Tunas: Jurnal Pendidikan Guru Sekolah Dasar 5, no. 2 (2020): 1-8

2 Neng Gustini, "Bimbingan Dan Konseling Melalui Pengembangan Akhlak Mulia Siswa Berbasis Pemikiran Al-Ghazali,” Tadris: Jurnal Keguruan Dan Ilmu Tarbiyah 1, no. 1 (2016): 1-14

${ }^{3}$ Nurochim Nurochim and Siti Ngaisah, "Analisis Isi Sikap Sosial Dalam Buku Ajar Pendidikan Agama Islam Dan Budi Pekerti," Al Hikmah: Journal of Education 2, no. 1 (2021): 37-52

${ }^{4}$ Befirman, "Pembentukan Akhlakqul Karimah Melalui Model Pembelajaran Pendidikan Jasmani Olahraga Dan Kesehatan Di Sekolah Dasar," Tadris: Jurnal Keguruan Dan Ilmu Tarbiyah 1, no. 1 (2016): 41-55

5 Farhat Abdullah, "Metode Pendidikan Karakter Nabi MUhammad SAW Di Madrasah," Tahdzib AlAkhlaq: Jurnal Pendidikan Islam 2, no. 2 (2019): 63-83 
dengan ilmu, iman, amal, dan takwa ${ }^{6}$. Keluarga dan sekolah menjadi lingkungan yang dapat mengajarkan dan menanamkan pendidikan akhlak ${ }^{7}$. Proses yang dilakukan dalam pendidikan akhlak membantu perkembangan dan pertumbuhan peserta didik didik agar menjadi orang yang beriman dan berakhlak mulia ${ }^{8}$. Perkembangan dan pertumbuhan akhlak dapat dilakukan dengan kebiasaan kegiatan yang dilakukan sesuai dengan ajaran nabi Muhammad SAW yang menjadi taulan untuk menyempunakan akhlak di dunia ini ${ }^{9}$.

Sifat dalam diri setiap manusia yang melekat sejak lahir dijiwa dilakukan dengan perbuatanperbuatan tanpa adanya paksaan dari orang lain dan perbuatan terpuji yang telah tertanam dalam dirinya 10. Membentuk pendidikan akhlak dilakukan dengan bertahap 1) akhlak dimiliki atas dasar dari perkembangan pengetahuan (knowing), dapat menbedakan perbuatan yang benar dan perbuatan yang salah agar dapat bertanggung jawab baik sebagai individu (fardhu 'ain) dan sebagai bagian dari masyarakat (fardhu kifayah), 2) mengidentifikasi tindakan korektif dan kebenaran yang dirasakan di balik tindakan. 3) identifikasi pengetahuan dan pemahaman tentang tindakan yang dipilih dan mempertahankan pilihan tindakan tersebut ('azm) ${ }^{11}$.

Pendidikan akhlak wajib dimulai sejak usia dini karena masa kanak-kanak adalah masa yang paling kondusif untuk menanamkan kebiasaan yang baik ${ }^{12}$. Kebiasan akhlak yang baik dapat meniru dari sikap dan tauladan dari akhlak rasulullah SAW dapat dilihat Alquran Ayat yang menjelaskan rasullulan diciptakan untuk menyempurnakan akhlak manusia. Karena itu, pendidikan akhlak terhadap anak, menjadi fokus utama dalam Islam ${ }^{13}$.

Akhlak merupakan sikap sepontan yang telah melekat pada diri seseorang, segala bentuk perilaku dilancarkan dengan iman, impementasi dilakukan menurut pandangan agama berjalan dengan baik, tindakan yang dilakukan dengan baik dikatakan sebagai akhlaqul karimah atau akhlaqul mahmudah dan sebalik- nya jika tindakan spontan dilakukan dengan jelek disebut sebagai akhlaqul

${ }^{6}$ Eva Latipah and Nur Faizatul Mardliyah, "Keterkaitan Kemampuan Berpikir Kritis Dengan AkhlakulKarimah Pada Siswa SMP Ma'had Islamy,” Jurnal Pendidikan Agama Islam 17, no. 1 (2020): 55-66.

${ }^{7}$ Eka Fitria Ningsih, “Jurnal Iqra' : Kajian Ilmu Pendidikan.," Jurnal Iqra' : Kajian Ilmu Pendidikan 1, no. 2 (2016): 191-217.

${ }^{8}$ Payiz Zawahir Munthoha and Ismail Suardi Wekke, "Pendidikan Akhlak Remaja Bagi Keluarga Kelas Menengah Perkotaan," Cendekia: Journal of Education and Society 15, no. 2 (2017): 241

9 Akis Indriana Rahayu, "Sifat-Sifat Rasulullah Saw Sebagai Dasar Pendidikan Karakter," Prosiding Seminar Nasional Dies Natalis 41 Utp Surakarta 1, no. 01 (2021): 19-26

${ }^{10}$ Sinta Fitriani, "Pendidikan Karakter Sebagai Upaya Menciptakan Akhlak Mulia Siswa Sekolah Dasar," ELSE (Elementary School Education Journal) : Jurnal Pendidikan Dan Pembelajaran Sekolah Dasar 3, no. 2 (2019): 229-38

${ }^{11}$ Nuraly Masum Aprily, "Nidzomul Ma’had Dalam Pendidikan Akhlak Di Pesantren Cipari Kabupaten Garut," Premiere Educandum : Jurnal Pendidikan Dasar Dan Pembelajaran 9, no. 2 (2019): 141

12 Ibrahim Bafadhol, "Pendidikan Akhlak Dalam Persfektif Islam," Jurnal Edukasi Islami Jurnal Pendidikan Islam 06, no. 12 (2017): 45-61.

${ }^{13}$ Fadlil Yani Ainusyamsi and Husni Husni, "Perspektif Al-Qur'an Tentang Pembebasan Manusia Melalui Pendidikan Akhlak," Jurnal Penelitian Pendidikan Islam 9, no. 1 (2021): 51 
Novela Aditiya, Sutrisno : Penanaman Nilai-Nilai Akhlak Berbasis Kegiatan Sunnah Rasulullah di Sekolah Dasar

madzmumah ${ }^{14}$. Tujuan penanaman nilai akhlak untuk mengembangan nilai berbudi pekerti yang dimiliki, bertingkah laku sesuai norman dan kebudayaan, berperangai sesuai adat istiadat yang baik berdasarkan ajaran Islam, serta menerima setiap kebagikan maupun keburupakan dengan hati ikhlas. Tindakan yang dilakukan dengan ikhlas dan dapat menerima reward yang didapat akan terwujud perbuatan-perbuatan terpuji terhindar dari perbuatan tercela yang lebih mementingkan urusan di dunia dan dari pada kepentingan akhirat sebagai bekal dikehidupan yang kekal ${ }^{15}$.

Penelitian tentang penanaman nilai-nilai akhlak melalui kegiatan sunah rasulullah belum banyak diteliti. Adapaun beberapan penelitian telah dilakukan sebelumnya metode penanaman nilai akhlak dengan pembiasan meneladani akhlak rasulullan dengan metode membaca atau menceritakan kisah melewati keteladanannya, perbuatan targhib dan tarhib, serta pengawasan dari untuk menanamkan nilai akhlak yang baik kepada peserta didik yang bersumber dari ajaran Alquran dan alHadits ${ }^{16}$. Nilai kebaikan dapat dijalankan dengan turun temurun dilingkungan keluarga, sekolah dan masyarakat apabila nilai tersebut sudah diadopsi makan akan dijadikan pegangan dan tuntutan ${ }^{17}$. Nilai akhlak yang diterapkan peserta didik diajarkan untuk berpuasa sunnah pada hari senin, hari kamis dan membiasakan sedekah (infaq) ${ }^{18}$. Membentuk akhlak peserta didik dapat memberikan reward sehingga peserta didik termotivasi pada pembelajaran ${ }^{19}$. Oleh karena itu, peneliti mengaji permasalan pokok dalam penelitian untuk mengetahui bagaimana penanaman nilai-nilai akhlak berbasis sunah rasulullah di SD IT Sahabat Qur'an.

\section{METODE PENELITIAN}

Penelitian ini mengacu pada pendekatan kualitatif deskriptif analitis untuk mendeskripsikan penanaman nilai-nilai akhlak berbasis kegiatan sunnah rasululllah di sekolah dasar. Penelitian ini dilakukan di SD IT Sahabat Qur'an beralamat di Kecamatan koba Kabupaten Bangka Tengah Provinsi

\footnotetext{
${ }^{14}$ Amin Zamroni, “Strategi Pendidikan Akhlak Pada Anak,” Sawwa: Jurnal Studi Gender 12, no. 2 (2017): 241

15 Fani Fadliyani, Yosep Farhan Dafik Sahal, and Muhamad Aris Munawar, "Implementasi Bina Pribadi Islam (BPI) Dalam Membina Akhlak Peserta Didik Di Sekolah Dasar Inspiratif Al-Ilham Kota Banjar,” Bestari Jurnal Studi Pendidikan Islam 17, no. 2 (2021): 165

16 Abdul Jabar Idhaudin, Akhmad Alim, and Abdul Hayyie Al Kattani, "Penerapan Model Pendidikan Akhlak Syaikh Utsaimin Di Sdit Al-Hidayah Bogor,” Jurnal As-Salam 3, no. 3 (2019): 53-66

17 Nirwani Jumala Nirwani Jumala and Abubakar Abubakar, "Internalisasi Nilai-Nilai Spiritual Islami Dalam Kegiatan Pendidikan,” Jurnal Serambi Ilmu 20, no. 1 (2019): 160

${ }^{18}$ Muhammad Amri, Saharuddin Saharuddin, and La Ode Ismail Ahmad, "The Implementation of Islamic Education: The Process of Instilling Akhlakul Karimah (Noble Characters) for Madrasah Tsanawiyah Students," Tadris: Jurnal Keguruan Dan Ilmu Tarbiyah 4, no. 1 (2019): 117-25

19 Teguh Yunianto, Suyadi Suyadi, and Suherman Suherman, "Pembelajaran Abad 21: Pengaruhnya Terhadap Pembentukan Karakter Akhlak Melalui Pembelajaran STAD Dan PBL Dalam Kurikulum 2013," Premiere Educandum : Jurnal Pendidikan Dasar Dan Pembelajaran 10, no. 2 (2020): 203
} 
Bangka Belitung. Peneli melakukan proses penelitian dari tanggal 18 November sampai 28 November 2021.

Penelitian yang dilalukan dengan mengumpulankan data hasil observasi dan wawancara. Observasi dilakukan selama 1 minggu dari tanggal 18 November sampai 25 Novemer 2021 sedangkan wawancara dilakukan melalui whatshap selama 3 hari dari tanggal 26 November 2021 sampai 28 November. Data dari penelitian ini bersumber dari wawancara yang dilakukan dengan 3 informan sebagai data primer dari infroman guru kelas, sedangkan data dari jurnal-jurnal sebelumnya merupakan data sekunder. Hasil wawancara dari informan melalui tahapan analisis reduksi data yang menggolongkan hasil informasi dengan topik permasalahan yang sama, penyajian pelaporan data yang telah digolongkan dan penarikan kesimpulan hasil penyampaian informan.

\section{HASIL DAN PEMBAHASAN \\ 1. Penguatan Akidah Peserta Didik}

Penguatan akidah yang diterapkan oleh pendidik yaitu untuk menanamkan kepribadian yang lebih baik dan tangguh menghadapai ringatan kehidupan selalu bergantung kepada allah SWT. Penguatan yang akidah yang bersumber kepada Allah SWT akan mengajarkan peserta didik untuk untuk senantiasa berharap dan memujinya. Berdasarkan hasil dari informan ibu D selaku wali kelas V sholiha. Beliau menyampaikan bahwa:

"saya selalu memberikan penguatan akidah kepada anak-anak melalui motivasi yang dilakukan setiap proses pembelajaran berlangsung, saat peserta didik melakukan kesalahan sebagai pendidik saya memberikan saran agar peserta didik tidak mengulangi kesalahan yang sama dan mengingkatkan setiap kegiatan yang dilakukan dapat dilihat oleh allah SWT. Peserta didik yang telah menyelesaikan tugas serta ulangan harian pada kolom nilai diberikan kata-kata yang dapat meningakatkan semangat dalam kegiatan belajar dan menerima hasil atas usaha yang peserta didik lakukan" (Infroman ibu D hari Jumat, 26 November 2021).

Dari hasil informan menyatakan bahwa akidah yang dapat diterapkan kepada peserta didik yaitu dapat menerima hasil yang dilakukan dengan usaha sendiri, tidak perlu khawatir, dan sedih apabilah mendapatkan nilai yang tidak sesuai dengan harapan yang diinginkan. Setiap perbuatan yang dilakukan oleh peserta didik baik ataupun buruk dapat dilihat oleh sang pencipta walaupun perbuatan dilakukan tanpa diketahui orang lain yang tidak melihatnya dan perbuatan yang dilakukan akan dipertanggung jawabkan di akhirat. Memberikan penanaman akidah kepada peserta didik bertujuan peserta didik dapat bersikap baik, tidak melanggar ajaran agama dan tidak melakukan perbuatan buruk yang melanggar norman ajaran agama.

Al-Madrasah: Jurnal Ilmiah Pendidikan Madrasah Ibtidaiyah Vol. 6, No. 1, Januari-Maret 2022 
Novela Aditiya, Sutrisno : Penanaman Nilai-Nilai Akhlak Berbasis Kegiatan Sunnah Rasulullah di Sekolah Dasar

\section{Pembiasan Shalat}

Proses pembelajaran yang dilakukan di SD IT sahabat qur'an dimulai pada pukul 07.15 sampai 16.00. Semua peserta didik melaksakan shalat di masjid yang dilaksakan dengan berjamaah dipimpin oleh ustadz secara bergeliran sesuai jadwal yang telah ditentukan (observasi hari Kamis 18 November 2021). Berdasarkan hasil dari infroman ibu M selaku guru mata pelajaran kelas III, V dan guru pemdamping kelas 2 sholeh. Beliau mengatakan bahwa:

“pembiasan shalat yang diteparkan di SD IT Sahabat Qur'an yaitu sebelum proses pembelajaran dimulai anak-anak melaksakan shalat sunnah dhuha, pada waktu zuhur melaksakan shalat dengan berjamaah serta melaksanakan shalat sunah qobliyah dan badiyah zuhur, dan pada waktu shalat ashar peserta didik melaksanakan secara berjamaah serta melaksanakan shalat qobliyah ashar. (infroman ibu M hari sabtu, 27 November 2021).

Dari hasil di atas menyatakan bahwa pembiasan shalat yang dilakukan di SD IT sahabat qur'an yaitu melaksanakan shalat sunah dhuha, shalat zuhur serta shalat sunah qobliyah dan badiyah pada waktu zuhur, dan melaksanakan shalat ashar serta shalat sunah qobliyah pada waktu ashar kegiatan shalat dilakukan dengan berjamaah.

\section{Membaca Alquran dan Menghafal Alquran (Tahsin dan Tahfiz)}

Nilai religius yang menjadi keunggulan di SD IT sahabat quran yaitu program tahfizh quran bagi peserta didik yang dilakukan dari kelas 1 sampai kelas V. kegiatan tahsin dan tahfiz dilakukan setiap hari disekolah. Setiap peserta diwajibkan membawa Alquran dan iqra setiap peserta didik mendapatkan meja untuk menyimpan Alquran pada saat kegiatan tahsin (observasi hari senin 21 November 2021). Berdasarkan hasil dari infroman ibu S wali kelas I sholiha, ibu M wali kelas III sholeh dan ibu D guru kelas $\mathrm{V}$ sholiha. Beliau mengatakan bahwa:

"peserta didik melaksanakan kegiatan tahsin pada pagi hari dan tahfish pada pagi hari atau siang hari tergantung jadwal yang dilakukan kegiatan ini dilakukan dengan wali kelas atau ustazah pendamping. Untuk di kelas 1 kegiatan tahfiz peserta didik mendengarkan ayat quran yang dibaca oleh ustazah kemudian peserta didik mengikuti. Peserta didik diminta untuk menghafalkan dihari berikutnya akan disetorkan hafalan ayat qur'an kepada guru pendamping di kelas" (informan ibu S hari kamis, November 2021).

"peserta didik melaksanakan kegiatan tahfish dengan metode halaqah yang dilaksankan sesuai jadwal yang ditentukan. Kegiatan dilakukan diruangkan halaqah atau ruang kelas. Kegiatan halaqah dibagi menjadi beberapa grup terdiri dari 5- 8 orang. Pada akhir semester peserta didik akan mengikuti ujian tahfiz di lakukan selama 1 minggu. Sebelum ujian tematik dan mata pelajaran lainya. Pada akhir semester peserta didik akan mengikuti kegiatan classmeting dengan lomba 
tahfiz yang setiap peserta didik sholeh dan sholeha dipisahkan" (informan ibu D hari Jum'at 26 November 2021)

"kegiatan tahsin dan tahfiz memiliki kendala yang dihadapi apabilah peserta didik yang sudah hafal ayat qur'an maka guru dan orang tua saling berkerja sama, setelah di rumah peserta didik melakukan kegiatan murajoah pada malam hari dengan umi atau abi di rumah agar hafalan yang mereka punya dapat dipertahakan. Kegiatan ini perlu dilakukan dengan disiplin" (infroman ibu M hari Sabtu 27 November 2021)

Dari hasil di atas menyatakan bahwa kegiatan tahsin dan tahfiz dilakukan sesuai jadwal yang telah ditentukan setiap kelasnya. Metode yang dilakukan dalam kegiatan tahfiz yaitu halaqah yang mengkelompokan beberapa grup kecil yang terdiri dari 5 sampai 8 peserta didik. Peserta didik melakukan setoran hafalan kepada wali kelas serta guru pendamping di kelasnya. Hafalan qur'an peserta didik akan dilakukan ujian pada akhir semester dan dilombakan pada kegiatan classmeting. Kaloborasi orang tua dan guru untuk mengaja hafalan peserta didik saat berada di sekolah dan di rumah dapat menjadi motivasi dalam menghafal asma allah SWT. Kedisiplinan saat berada di rumah untuk melakukan murajoah bersama keluarga pada malam hari.

\section{Pakaian dan Pemisahan Ruang Kelas Laki-Laki dan Perempuan}

Seragam yang diterapkan di SD IT Sahabat Qur'an sesuai dengan Syariat berpakaiannya umat muslim baik laki-laki dan perempuan. Peserta didik yang perempuan diwajibankan untuk menutup aurat yang sempurna, memakai jilbab dan memakai gamis. Ruang kelas peserta didik dipisakan, laki-laki di sebelah utara dan perempuan di sebelah selatan. Peserta didik perempuan dibebaskan untuk memakai jadar karena memakai jadar sunah yang dianjurkan nabi Muhammad SAW agar anak perempuan dapat menjaga rasa malu terhadap yang bukan mahram (observasi hari selasa, 22 November 2021).

"pakaian yang digunakan peserta didik dicontoh dengan ustazah yang mengajar di sana. Ustazah yang mengajar mengunakan seragam yang menutup aurat dengan sempurna dan dilarang untuk memakai pakain yang ketat. Jilbab yang digunakan harus melewai dada dan banyak ustazah yang memakai cadar. Memberikan contoh yang baik, akan memberikan efek yang positif bagi abad untuk mengikuti kebiasaan yang dilakukan oleh orang dewasa disekitarnya. Laki-laki dan perempuan dilarang untuk berada dilingkungan yang sama dan dilakukan pemisahan ruang kelas dan ruang bermain. Pemisahan yang dilakukan agar peserta didik dimulai sejak dini diajarkan untuk tidak bercampur baur antara peserta didik yang berbeda jenis kelamin dan menumbuhkan rasa malu pada diri peserta didik. Setiap kelas akan didampingi oleh 2 ustadz atau ustazah yang menjadi wali kelas serta guru pendamping” (informan ibu D hari Jum'at, 26 November 2021)

Pembiasan seragam yang diterapkan di SD IT Sahabat Qur'an dapat berdampak baik terhadap akhlak peserta didik. Peserta didik dapat menerapkannya bukan hanya dilingungan sekolah tetapi juga 
Novela Aditiya, Sutrisno : Penanaman Nilai-Nilai Akhlak Berbasis Kegiatan Sunnah Rasulullah di Sekolah Dasar

dapat diterapkan dilingkungan masyarakat. Rasa malu pada diri peserta didik telah muncul karena sudah mempelajari hal-hal yang harus dilakukan sebagai seorang muslim sesuai dengan sunah rasulullah SAW. Pembiasan yang telah diterapkan di sekolah dapat berhasil apabilah peserta didik menerapkannya di lingkungan keluarga serta masyarakat (observasi hari jum 'at, 19 November 2021).

Berdasarkan hasil di atas menyatakan bahwa pakaian dan adab yang diterapkan sejak dini sesuai dengan sunah rasulullah SAW dapat memberikan efek yang baik untuk perkembangan peserta didik. Peserta didik dapat mengetahui bahwa bergaul dengan laki-laki dan perempuan mempunyai batasan. Rasa malu yang muncul apabilah tidak mengunakan jilbab saat keluar rumah hal ini akan menjadi pondasi yang baik sebagai bekal terhindar dari perilaku yang kurang baik dari orang lain.

\section{Akhlak dan Abad Islami}

Akhlak dan abad yang diterapkan di SD IT Sahabat Alquran diterapkan sesuai dengan suri tauladan nabi Muhammad SAW. Peserta didik melaksankan kegiatan pembelajaran full days school sehingga peserta didik membawa bekal yang telah disiap oleh orang tua di rumah. Peserta didik diwajibkan untuk tidur siang selama 1 jam setelah shalat zuhur dilaksanakan (observasi Hari Rabu, 23 November 2021).

"setiap pagi hari peserta didik memulai kegiatan pembelajaran dengan membaca doa, pada jam istirahat peserta didik makan siang dan berdoa bersama, ustazah mengingatkan untuk makan dan minum menggunakan tangan kanan serta duduk sesuai dengan sunah rasulullah SAW. Siang hari peserta didik melaksakan tidur yang dimulai dengan berdoa terlebih dulu. Melaksanakan shalat dengan berjamaah, dan melakukan murajoah hafalan setelah melaksanakan shalat wajib" (infroman Ibu M hari Sabtu, 27 November 2021).

Berdasarkan hasil di atas menyatakan bahwa kegiatan akhlak dan adab yang dilakukan oleh seorang muslim harus sesuai dengan kaidah-kaidah yang telah diteparkan dalam agama Islam dan sunnah nabi Muhammad SAW. Setiap melaksanakan kegiatan dimulai dengan berdoa, membaca basmallah, dan memulai dengan menggunakan tangan kanan atau kaki kanan.

\section{KESIMPULAN}

Penanaman nilai-nilai akhlak berdasarkan kegiatan sunnah rasulullah di SD IT Sahabat Qur'an yaitu penguatan akidah yang bersumber dari ajaran Allah SWT, pembiasan shalat sunah dhuda, qobliyah, badiyah, dan shalat wajib zuhur dan ashar yang dilaksankan dengan berjamaah, kegiatan tahsin dan tahfiz yang telah ditentukan kegiatannya sesuai jadwal, pakaian yang sesuai dengn syariat Islam dan pemisahan ruang kelas laki-laki dan perempuan, akhlak dan abad Islam yang dilakukan berdasarkan sunnah rasulullah. 


\section{SARAN dan REKOMENDASI}

Beberapa saran dan rekomenadi berdasarkan penelitian yang sudah dilakukan sebelumnya: Pendidik diharapakan dapat menanamkan nilai akhlak sesuai dengan suri tauladan Rasulullah SAW sejak dini untuk menjadi bekal dalam menjalankan kehidupan, pihak sekolah dapat merangcang strategi dalam menanamkan nilai karakter sesuai dengan tingkat kelas dan perkembangan peserta didik, dan peneli selanjutnya dapat mengiimplemetasi penelitian yang permasalannya menganai pembiasan menanamkan nilai akhlak sejak dini.

\section{DAFTAR PUSTAKA}

Abdullah, Farhat. "Metode Pendidikan Karakter Nabi MUhammad SAW Di Madrasah." Tahdzib Al-Akhlaq: Jurnal Pendidikan Islam 2, no. 2 (2019): 63-83. https://doi.org/10.34005/tahdzib.v2i2.516.

Ainusyamsi, Fadlil Yani, and Husni Husni. "Perspektif Alquran Tentang Pembebasan Manusia Melalui Pendidikan Akhlak.” Jurnal Penelitian Pendidikan Islam 9, no. 1 (2021): 51. https://doi.org/10.36667/jppi.v9i1.670.

Amri, Muhammad, Saharuddin Saharuddin, and La Ode Ismail Ahmad. "The Implementation of Islamic Education: The Process of Instilling Akhlakul Karimah (Noble Characters) for Madrasah Tsanawiyah Students." Tadris: Jurnal Keguruan Dan Ilmu Tarbiyah 4, no. 1 (2019): 117-25. https://doi.org/10.24042/tadris.v4i1.4070.

Aprily, Nuraly Masum. "Nidzomul Ma'had Dalam Pendidikan Akhlak Di Pesantren Cipari Kabupaten Garut." Premiere Educandum: Jurnal Pendidikan Dasar Dan Pembelajaran 9, no. 2 (2019): 141. https://doi.org/10.25273/pe.v9i2.4987.

Bafadhol, Ibrahim. "Pendidikan Akhlak Dalam Persfektif Islam.” Jurnal Edukasi Islami Jurnal Pendidikan Islam 06, no. 12 (2017): 45-61.

Befirman. "Pembentukan Akhlakqul Karimah Melalui Model Pembelajaran Pendidikan Jasmani Olahraga Dan Kesehatan Di Sekolah Dasar." Tadris: Jurnal Keguruan Dan Ilmu $\begin{array}{lllll}\text { Tarbiyah } & 1, & \text { no. } & 1 & \text { (2016): }\end{array}$ http://ejournal.radenintan.ac.id/index.php/tadris\%0Ahttp://moraref.or.id/record/view/486 72.

Fadliyani, Fani, Yosep Farhan Dafik Sahal, and Muhamad Aris Munawar. "Implementasi Bina Pribadi Islam (BPI) Dalam Membina Akhlak Peserta Didik Di Sekolah Dasar Inspiratif Al-Ilham Kota Banjar.” Bestari | Jurnal Studi Pendidikan Islam 17, no. 2 (2021): 165. https://doi.org/10.36667/bestari.v17i2.512.

Fitriani, Sinta. "Pendidikan Karakter Sebagai Upaya Menciptakan Akhlak Mulia Siswa Sekolah Dasar." ELSE (Elementary School Education Journal): Jurnal Pendidikan Dan Pembelajaran Sekolah Dasar 3, no. 2 (2019): 229-38. https://doi.org/10.30651/else.v3i2.3011.

Gustini, Neng. "Bimbingan Dan Konseling Melalui Pengembangan Akhlak Mulia Siswa Berbasis Pemikiran Al-Ghazali." Tadris: Jurnal Keguruan Dan Ilmu Tarbiyah 1, no. 1 
Novela Aditiya, Sutrisno : Penanaman Nilai-Nilai Akhlak Berbasis Kegiatan Sunnah Rasulullah di Sekolah Dasar

(2016): 1-14. www.unissula.ac.id.

Idhaudin, Abdul Jabar, Akhmad Alim, and Abdul Hayyie Al Kattani. "Penerapan Model Pendidikan Akhlak Syaikh Utsaimin Di Sdit Al-Hidayah Bogor." Jurnal As-Salam 3, no. 3 (2019): 53-66. https://doi.org/10.37249/as-salam.v3i3.137.

Latipah, Eva, and Nur Faizatul Mardliyah. "Keterkaitan Kemampuan Berpikir Kritis Dengan Akhlakul-Karimah Pada Siswa SMP Ma'had Islamy.” Jurnal Pendidikan Agama Islam 17, no. 1 (2020): 55-66.

Munthoha, Payiz Zawahir, and Ismail Suardi Wekke. "Pendidikan Akhlak Remaja Bagi Keluarga Kelas Menengah Perkotaan." Cendekia: Journal of Education and Society 15, no. 2 (2017): 241. https://doi.org/10.21154/cendekia.v15i2.1153.

Ningsih, Eka Fitria. “Jurnal Iqra': Kajian Ilmu Pendidikan.” Jurnal Iqra': Kajian Ilmu $\begin{array}{lllll}\text { Pendidikan } & 1, & \text { no. } & 2 & \text { (2016): }\end{array}$ https://journal.iaimnumetrolampung.ac.id/index.php/ji/article/view/73.

Nirwani Jumala, Nirwani Jumala, and Abubakar Abubakar. "Internalisasi Nilai-Nilai Spiritual Islami Dalam Kegiatan Pendidikan.” Jurnal Serambi Ilmu 20, no. 1 (2019): 160. https://doi.org/10.32672/si.v20i1.1000.

Nurochim, Nurochim, and Siti Ngaisah. "Analisis Isi Sikap Sosial Dalam Buku Ajar Pendidikan Agama Islam Dan Budi Pekerti." Al Hikmah: Journal of Education 2, no. 1 (2021): 3752. https://doi.org/10.54168/ahje.v2i1.29.

Rahayu, Akis Indriana. "Sifat-Sifat Rasulullah Saw Sebagai Dasar Pendidikan Karakter." Prosiding Seminar Nasional Dies Natalis 41 Utp Surakarta 1, no. 01 (2021): 19-26. https://doi.org/10.36728/semnasutp.v1i01.5.

Yunianto, Teguh, Suyadi Suyadi, and Suherman Suherman. "Pembelajaran Abad 21: Pengaruhnya Terhadap Pembentukan Karakter Akhlak Melalui Pembelajaran STAD Dan PBL Dalam Kurikulum 2013." Premiere Educandum: Jurnal Pendidikan Dasar Dan Pembelajaran 10, no. 2 (2020): 203. https://doi.org/10.25273/pe.v10i2.6339.

Zamroni, Amin. "Strategi Pendidikan Akhlak Pada Anak." Sawwa: Jurnal Studi Gender 12, no. 2 (2017): 241. https://doi.org/10.21580/sa.v12i2.1544.

Zannah, Fathul. "Integrasi Nilai-Nilai Pendidikan Karakter Berbasis Al Qur'an.” Tunas: Jurnal Pendidikan Guru Sekolah Dasar 5, no. 2 (2020): 1-8. https://doi.org/10.33084/tunas.v5i2.1233. 